\title{
IMPROVEMENT OF DIGGING SHARES OF ROOT HARVESTING MACHINES BASED ON RHEOLOGICAL MODEL OF SOIL STATE
}

\author{
Andrei Kalinin, Igor Teplinsky, Vycheslav Ruzhev \\ Saint-Petersburg State Agrarian University, Russia \\ andrkalinin@yandex.ru, teplinskij.igor.zinovevich@gmail.com,ruzhev_va@mail.ru
}

\begin{abstract}
Harvesting of root crops is one of the most important technological processes, which accounts for more than $30 \%$ of total costs in the performance of all technological operations. The most difficult technological process during the potato harvesting is the process of soil separation, which consists in the destruction of soil clods, and further their separation on the web elevators. It was established that the ability of soil to separate is determined by its state. These factors affect the ability to use potato harvesters and determine their efficiency. On loamy and clayey soils, the separation efficiency is reduced. The separation of the soil becomes much more difficult with increased its moisture. In order to intensify the process of destruction of the soil layer it is proposed to form in it destructive stresses along the entire path of movement along the working surface of the share. This can be achieved by creating a share with a curved working surface. The design of share working surface is based on the CoulombMohr strength theory, according to which material failure occurs at various combinations of the main normal compression stresses and tension. At the same time, it is taken into account that the compressive strength of the soil is 3-7, and with a shear of 2.4-4.3 and more times, exceeds the tensile strength. Therefore, it is advisable to induce tensile stresses in the soil layer. Field trials have shown that replacing a flat share on a potato harvester with a new share with a curved working surface increases the efficiency of its technological process by intensifying the process of destruction of the soil layer.
\end{abstract}

Keywords: Soil; rheological model; stress; working surface.

\section{Introduction}

Increasing the efficiency of a potato harvester is largely determined by the ability of its working elements to destroy and separate the tuberous layer [1]. The ability of the soil to separate is determined by its moisture content, depending on the parameters of which they distinguish between solid, plastic and fluid states [2]. Separation of the soil during potato harvesting becomes much more complicated with its high humidity, which is typical for the conditions of the functioning of harvesting machines in the North-West of the European continent. In the designs of potato harvesters for the destruction and separation of soil, flat digging shares and belted web chain are now predominantly used $[3,4]$. To increase the efficiency of the technological processes of the operation of potato harvesters the machines designers are improving the working elements that provide the intensification of the mechanical effect on the tuberous soil layer [5]. However, this leads to a significant complication in the design of harvesting machines and an increase in their cost. The goal of this work is to improve the quality of separation of the heap of a potato harvester by development the shape of the working surface of the digging share, which allows for an intensive process of soil destruction, facilitating the operation of separation systems. The results of the studies carried out in the SPbGAU showed that the installation of the proposed design of digging share on the DR 1500 potato harvester made it possible to significantly improve the quality of separation of the heap and fully ensure compliance with the requirements of the technological regulations.

\section{Materials and methods}

A model of the technological process of functioning of a potato harvester as an object of soil destruction and separation control in the form of a scheme is shown in Fig. 1. The conditions of functioning that affect the course of the technological process of the object are random in the probabilistic and statistical sense of the process of unevenness of the soil surface $Z_{n}(t)$ and soil cone index $R(t)$, as well as its moisture $W(t)$. These parameters of the soil state affect the first element of the model - the digging share 1 , which cuts the tuberous layer, partially destroys it and feeds the heap in the form of a random process $K_{1}(t)$ to the belted wad chain 2 . The belted web chain 2 splits the heap into tuber flow as a random process $K_{2}(t)$ and impurities flow $E(t)$. Tuber flow $K_{2}(t)$ enters the inspection table 3, where impurities are released $E_{2}(t)$ and further potatoes flow as a random process $K_{Y}(t)$ delivered in the bunker of a potato harvester. 
The depth of work of the digging shares is taken as the tuning parameters of the model $h_{\mathrm{H}}$ as well as the harvester speed $V_{H}$.

The efficiency of the separation system of potato harvesters was assessed by the relative content of soil impurities in the potato heap $K_{y}(t)$ in the bunker. According to the requirements of the technological regulations for the operation of potato harvesters, the purity of tubers collected in the bunker must be at least $80 \%$.

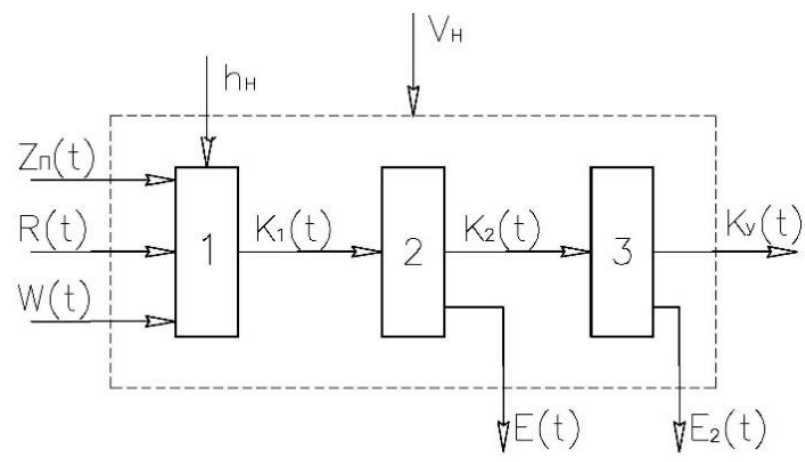

Fig. 1. Scheme of a model controlling soil destruction and separation by a potato harvester

Experimental studies carried out in the farm with a potato harvester DR 1500 equipped with a serial digging flat share have shown that on heavy loamy soils the requirements of the regulations are not fulfilled. So, on the digging depth of $20 \mathrm{~cm}$ and the working speed of 5 and $7 \mathrm{~km} \cdot \mathrm{h}^{-1}$ the average values of the potato purity indicator in the combine bunker were $71 \%$ and $66 \%$, respectively.

Analyzing the process of the separating system of the harvester, it is clear that the most intensive destruction of the soil is carried out on the bars of the belted web chain immediately after digging up by the share. Most of the working surface of this share performs a transport function and does not create conditions for its crumbling. To improve the efficiency of the separation system of the potato harvester, it is necessary to improve the form of the share. The purpose of this change is to ensure intensive destruction of the soil layer during its movement on the surface of the share. For this goal we will use the rheological model of the soil presented in the form of a continuous deformable medium, which has a certain structure and internal connections between the elements [6; 7].

When digging shares of a potato harvester interact with the soil, the mutual arrangement of soil elements changes, which leads to the appearance of volumetric deformations inside the soil, as well as shear deformation, which results in a change in the structure of this layer and the underlying horizon [8; 9]. Let us single out in a deformable medium an elementary parallelepiped, on the faces of which under the action of external disturbances normal $\sigma_{1}, \sigma_{2}, \sigma_{3}$ and tangential $\tau_{i j}$ stresses arise (Fig.2). The greatest tangential stress $\tau_{\max }$ leading to the destruction of the soil element is formed in a plane that has an equal slope to the direction of normal stresses having the highest absolute values [10]. The stress state arising in an elementary volume under an external action can be represented as a stress tensor $T_{S}$, which is described by the expression (1)

$$
T_{S}=\left\{\begin{array}{ccc}
\sigma_{1} & \tau_{1,2} & \tau_{1,3} \\
\tau_{2,1} & \sigma_{2} & \tau_{2,3} \\
\tau_{3,1} & \tau_{3,2} & \sigma_{3}
\end{array}\right.
$$

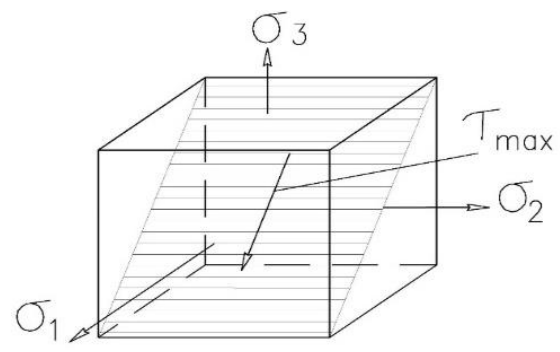

Fig. 2. Scheme of stresses acting on an elementary soil sample 
The general rheological model of the soil state consists of a model of volumetric deformations and a model of deformation of shape change [11], which can be represented as (2)

$$
\left\{\begin{array}{c}
\frac{d \gamma_{i j}}{d t}=\frac{A_{(p)}}{\sigma_{(p)} t} \tau_{i j}+\frac{1}{\sigma_{(p)}} \times \frac{d \tau_{i j}}{d t} ; \tau_{i j}<\tau_{\max } \\
\frac{d \gamma_{i j}}{d t}=\frac{A_{(p)}}{\sigma_{(p)} t} \tau_{i j}+\frac{1}{G_{(p)}} \times \frac{d \tau_{i j}}{d t}+\frac{\tau_{i j}-\tau_{\max }}{\eta(t)} ; \tau_{i j} \geq \tau_{\max } \\
\frac{d \sigma_{i}}{d t}=E_{(p)} \frac{d \varepsilon_{i j}}{d t}-\frac{E_{(p)}}{\mu_{(\sigma)}} \sigma_{i j}
\end{array}\right.
$$

where $\gamma_{i j}$-shear deformation;

$A_{(p)}$ - empirical coefficient for determining creep;

$G$ - instantaneous shear modulus;

$\eta$ - shear viscosity coefficient;

$\mu$ - coefficient of viscosity at volumetric deformation;

$\sigma_{p}=\frac{\sigma_{1}+\sigma_{2}+\sigma_{3}}{3}-$ average normal stress;

$E_{(p)}$ - modulus of elasticity during volumetric deformation;

$\varepsilon$ - angular deformations.

The analysis of the presented rheological model of the soil state showed that the results of the action of the tillage tools on the soil depend on the distribution of stress fields in it that arise in the treated layer. With the destruction of the soil layer during the harvesting of potatoes, we use the regularities established by the Coulomb-Mohr theory of strength, according to which the shear stresses at the shear site in the state of ultimate equilibrium of the soil element are proportional to the normal stresses acting on the elementary volume. Fig. 3 shows a graphical interpretation of this regularity, taking into account such parameters of the soil state as the angle of internal friction $\varphi$ and the coefficient of adhesion $\mathrm{C}$ corresponding to the strength of the soil at the shear site at zero normal stress [12].

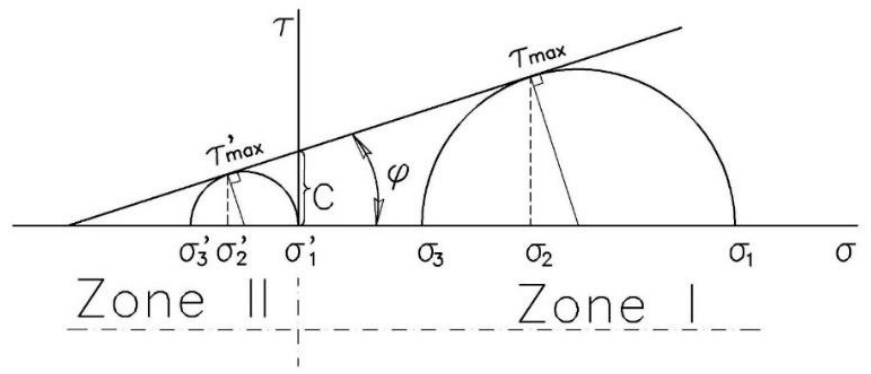

Fig. 3. Graphic interpretation of the action of the law of strength in the soil

According to the Coulomb - Mohr theory, the destruction of the soil sample occurs when the shear stresses $\tau_{\mathrm{ij}}$ exceed the limiting value $\tau_{\max }$ [13]. Analysis of Fig. 3 showed that the occurrence of limiting shear stresses $\tau_{\max }$ occurs under the influence of positive $\sigma_{i}$ and negative $\sigma^{\prime}{ }_{i}$ values of normal stresses acting on the edge of the elementary soil particle. Let us conditionally divide the area of influence of normal stresses acting on the edge of the elementary soil particle into two zones. In zone I, the destruction of the sample occurs under the action of normal stresses, which have positive values, and in zone II - negative ones. Thus, the destruction of the material in zone I occurs due to the compression of the soil element and in zone II when it is stretched. It should be noted that the limiting values of the shear stresses in zone I significantly exceed the shear stresses at which the destruction of the soil sample occurs in zone II. This means that, when a stressed state is created inside the soil in which negative values of normal stresses appear on the edges of the elementary volumes, the external forces necessary for crumbling the soil layer are significantly reduced.

On the basis of the theoretical studies of the regularity of the destruction of cohesive soils shown in Fig. 3 the improvement of the digging working body of the potato harvester was carried out by changing the shape of its working surface. This ensured the formation of a state with a predominance of negative values of normal stresses within the soil layer.

The longitudinal profile of the experimental share is a curved surface, the first part of which is concave and the second convex (Fig. 4). The soil layer moving along the concave surface experiences 
bilateral compression under the action of the friction force of the layer against the plow surface, as well as pressure from the previous massif, which leads to a reduction in the size of the soil element "abcd" in the longitudinal and vertical directions by $\Delta t$ and $\Delta r$, respectively [14]. Normal stresses $\sigma_{1}$ and $\sigma_{3}$ act on the edges of the soil element, which lead to a certain increase in density inside it due to a reduction in pore sizes, and then to its destruction when the shear stresses $\tau_{i j}$ reach the limiting value $\tau_{\max }$. On the concave section of the digging share positive values of the normal stress prevail, corresponding to zone I in the diagram shown in Fig. 3. With the transition of the soil layer to the convex surface the dimensions of the soil element begin to increase by the values of $\Delta t$ and $\Delta r$ due to stretching under the action of adhesion forces and the friction force of the layer on the shares surface. Normal stresses with negative values appear on the edges of this element, corresponding to zone II (Fig. 3), under the action of which a more intense destruction of the soil layer occurs due to the fact that the tangential stress in this section $\tau^{\prime}{ }_{\max }$ is much less than during its movement along the concave part of the digging share.

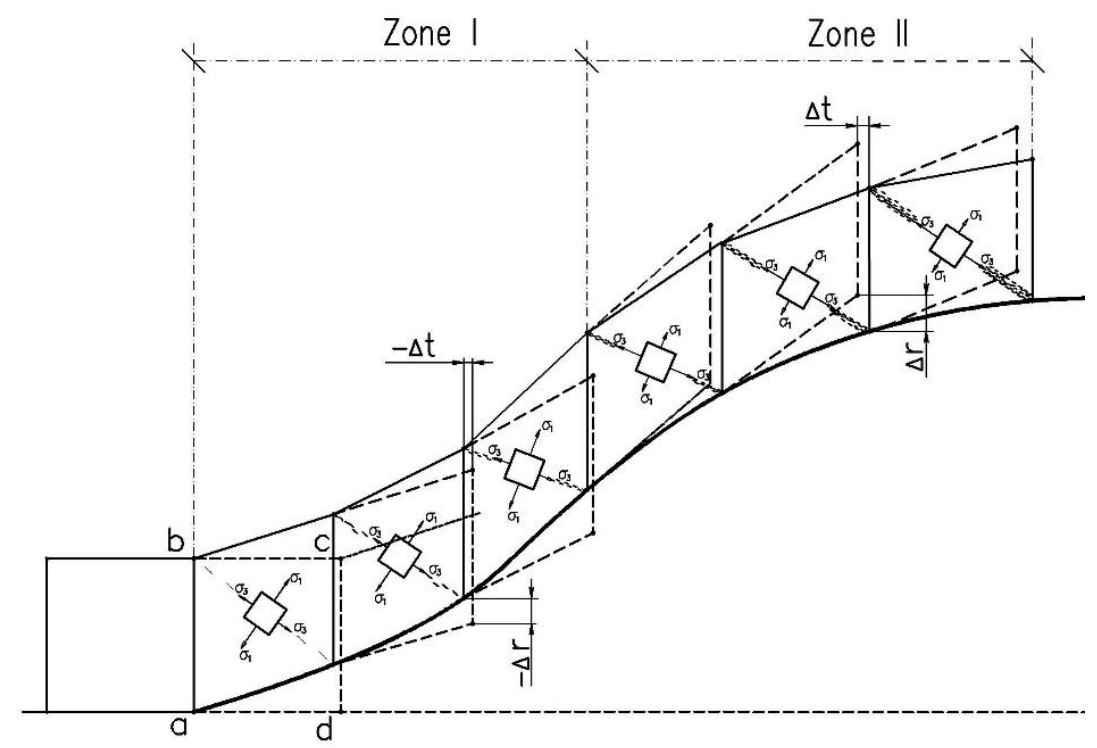

Fig. 4. Diagram of the stress state of the soil layer on the improved share in the longitudinal plane

In the transverse plane, the working surface of the share forms an arc (Fig. 5). During the movement of the soil layer along the experimental share in the transverse plane the distance between the soil elements increases, because the length of the arc is greater than the width of the share in the front side. Under the action of the forces of adhesion and the force of friction of the soil against steel the soil massif begins to stretch and the dimensions of the elementary soil particle increase by the values of $\Delta S$ and $\Delta r$. Normal stresses $\sigma_{2}$ and $\sigma_{3}$, which have negative values, act on the edges of the soil element. The stresses arising in the soil layer in the transverse plane correspond to zone II, which provides conditions for effective soil crumbling with minimal energy consumption.

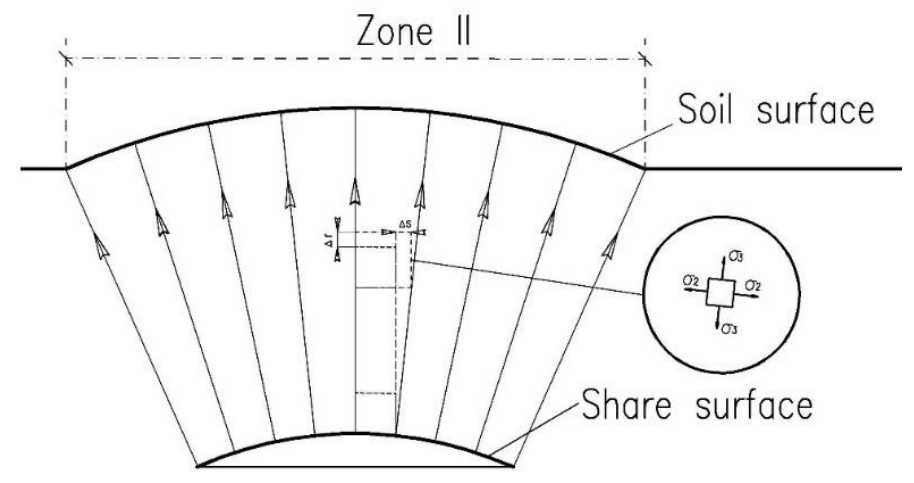

Fig. 5. Scheme of the stress state of the soil layer on the improved share in the transverse plane 
When the soil layer moves along the working surface of the experimental share, an alternating load acts on it, which at the initial stage leads to partial destruction of the soil massif under the action of compressive forces and at the second stage its three-sided stretching occurs, which provides intensification of the soil crumbling process on the digging share. It should be noted that on a serial share the destruction of the soil layer is provided only due to the action of compression forces with the undercut massif transitions to the inclined surface of the share. This effect leads to additional soil compaction, which further complicates the separation of the heap on the potato harvester [15].

To assess the intensity of soil destruction under the influence of the share shape the statistical characteristics of the potato heap $K_{Y}(t)$ entering the combine bunker obtained during experimental studies in production conditions were used. For this purpose, the estimates of the mathematical expectation $m_{k}$, the standard deviation $\sigma_{\mathrm{k}}$ and the coefficient of variation $V_{k}$ of the random process $K_{Y}(t)$ were calculated. In this case, the control interval $L_{k}$ was $300 \mathrm{~m}$, the control step for sampling was $\Delta l=10 \mathrm{~m}$, the number of samples was 30 . Sampling was carried out by taking samples of a heap of potatoes at the exit of the inspection table. Then was done weighing of the total volume of the sample and the extracted soil elements.

\section{Results and discussion}

On the basis of the results of the theoretical studies carried out the improvement of the serial digging share of the potato harvester performed by forming its three-dimensional working surface. For this purpose, a special shaped pad is installed on the serial digging share consisting of plates with an individual longitudinal profile (Fig. 6). The combination of these plates forms a three-dimensional working surface, the longitudinal and transverse profile of which changes along the length of the share, providing as the layer moves along the digging working body a three-sided alternating action on the soil.

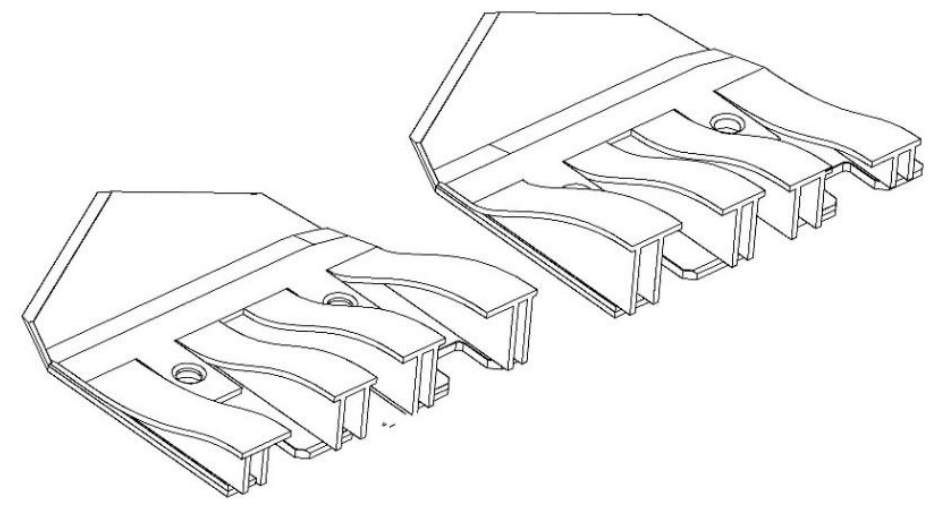

Fig. 6. Scheme of the experimental share of a potato harvester

The trial of the experimental share was carried out in the farm during the harvesting of potatoes on heavy loamy soils. The potato yield was $32.4 \mathrm{t} \cdot \mathrm{h}^{-1} \mathrm{a}$. The studies of the functioning process of the serial and experimental plowshares were carried out when the combine was adjusted to the same digging depth $h_{H}=24 \mathrm{~cm}$. The setting values of the $\mathrm{V}_{\mathrm{H}}$ potato harvester speed were $5 \mathrm{~km} \cdot \mathrm{h}^{-1}$ and $7 \mathrm{~km} \cdot \mathrm{h}^{-1}$. Soil moisture at the time of harvest was $26 \%$. The results of the research of the digging shares are given in the table, which presents the estimates of the statistical characteristics of the process of the quality of the potato heap $K_{Y}(t)$ under various operating modes of the potato harvester.

Estimates of the statistical characteristics of the quality of the potato heap entering the bunker of the potato harvester

Table 1

\begin{tabular}{|c|c|c|c|c|}
\hline \multirow{2}{*}{$\begin{array}{c}\text { Estimates of the } \\
\text { statistical } \\
\text { characteristics of the } \\
\text { process } K_{Y}(t)\end{array}$} & \multicolumn{2}{|c|}{$V_{H}=5 \mathrm{~km} \cdot \mathrm{h}^{-1}$} & \multicolumn{2}{|c|}{$V_{H}=7 \mathrm{~km} \cdot \mathrm{h}^{-1}$} \\
\hline & Serial share & $\begin{array}{c}\text { Experimental } \\
\text { share }\end{array}$ & Serial share & $\begin{array}{c}\text { Experimental } \\
\text { share }\end{array}$ \\
\hline$m, \%$ & 71.2 & 84.2 & 66.3 & 90.4 \\
\hline$\sigma, \%$ & 11.2 & 3.9 & 11.1 & 13.9 \\
\hline$V, \%$ & 15.7 & 4.6 & 16.7 & 15.4 \\
\hline
\end{tabular}


The analysis of the data presented in the table showed that, when a potato harvester equipped with serial digging shares is operating in conditions of increased soil moisture, the quality of the harvested heap does not meet the requirements of the technological regulations at the established speed modes of the combine. So, at a speed of $5 \mathrm{~km} \cdot \mathrm{h}^{-1}$ the estimate of the mathematical expectation of the process $K_{Y}(t)$ is $71.2 \%$ and at a working speed of $7 \mathrm{~km} \cdot \mathrm{h}^{-1}-66.3 \%$. These values of the quality indicator do not reach the permissible values established by the technological regulations, which is $80 \%$. Equipping a potato harvester with an experimental share provides a higher quality of separation of the heap due to more intensive destruction of the soil layer. At a working speed of $5 \mathrm{~km} \cdot \mathrm{h}^{-1}$ the estimate of the mathematical expectation of the potato heap quality process $K_{Y}(t)$ is $84.2 \%$ and at a speed of $7 \mathrm{~km} \cdot \mathrm{h}^{-1}-90.4 \%$.

\section{Conclusions}

1. The proposed shape of the working surface of the digging shares, which has a three-dimensional working surface, made it possible to ensure intensive destruction of the soil layer during its movement to the belted web chain due to the formation of alternating loads.

2. The experimental studies have shown that the use of the proposed digging share made it possible to increase the working speed of the potato harvester from 5 to $7 \mathrm{~km} \cdot \mathrm{h}^{-1}$, while meeting the requirements of the technological regulations for the indicator of the purity of the potato heap. So, at a speed of $5 \mathrm{~km} \cdot \mathrm{h}^{-1}$, estimates of the mathematical expectation of the process of purity of separation of a potato heap are $84.2 \%$, and at a speed of $7 \mathrm{~km} \cdot \mathrm{h}^{-1}-90.4 \%$.

3. The carried out improvement of the experimental digging share makes it possible to provide the required quality of harvesting in conditions of high soil moisture.

\section{References}

[1] Ibrahim M.M., Attia M.F. Development and evaluation of potato digger suitable for smallholdings. The 18th. Annual Conference of the Misr Soc. of Ag. Eng., 26-27 October, 2011, pp. 1-24.

[2] Campbell D.J. A review of the clod problem in potato production. Journal of Agricultural Engineering Research. Volume 27, Issue 5, 1982, pp. Pages 373-395. DOI:/10.1016/00218634(82)90077-4.

[3] Wei Z C, Li H W et al. Experiment and analysis of potato-soil separation based on impact recording technology. Int O Agric \& Biol Eng, Vol. 12 No5, 2019, pp. 71-80.

[4] Chutcheva Y. et al. Feasibility study of the optimal type of a potato harvester for the conditions of the Moscow region. IOP Conf. Series: Earth and Environmental Science 274 (2019) 012045. DOI: 10.1088/1755-1315/274/1/012045

[5] Zhbanov N. et al. Improvement of the working bodies of the harvesting machines by means of the use of composite materials. BIO Web Conf. 1700191 (2020). DOI: 10.1051/bioconf/20201700191

[6] Kulhawy F H. On the evaluation of soil properties [J]. ASCE Geotechnical Special Publication, 1992, 31: pp. 95-115.

[7] Kalinin A.B., Teplinsky I.Z., Ustroev A.A., Kudryavtsev P.P. Selection and substantiation of cultivator adjustment parameters for differential soil treatment on potato based on the rheology state of soil horizons. IOP Conference Series: Materials Science and Engineering. 2019. pp. 012-025.

[8] Ozoemena A. Ani et al. Overview of soil-machine interaction studies in soil bins. Soil and Tillage Research, Volume 175, 2018, pp. 13-27, doi.org/10.1016/j.still.2017.08.002.

[9] Kalinin A., Kalinina V., Teplinsky I., RuzhevV. Selection and justification of potato inter row tillage systems based on development of dynamic model of heat and moisture transfer between soil layers. Engineering for rural development ( $19^{\text {th }}$ International Scientific Conference Jelgava, 2022.05.2020, Latvia), pp. 819-825. DOI: 10.22616/ERDev2020.19.TF191

[10] Burland J.B. On the compressibility and shear strength of natural clays. Geotechnique, 1990, Vol. 40, No.3, pp. 329-378.

[11]Калинин А.Б., Теплинский И.З., Смелик О.В. Реологическая модель почвы как объекта формирования требуемой плотности в заданном слое // Известия Санкт-Петербургского государственного аграрного университета. - 2012. - № 29. - С. 248-255. Kalinin A.B., Teplinsky I.Z., Smelik O.V. Rheological model of soil as an object of formation of the required density in a given layer. Bulletin of the St. Petersburg State Agrarian University. 2012. № 29. pp. 248-255. (In Russian). 
[12] Fredland D.G., H. Rohardjo. Soil mechanics for unsaturated soils. John Wiley \& Sons, New York, 1993, $517 \mathrm{pp}$.

[13] Griffiths D. Failure Criteria Interpretation Based on Mohr-Coulomb Friction. Journal of Geotechnical Engineering. 1990, 116. DOI: 10.1061/(ASCE)0733-9410(1990)116:6(986)

[14] Панов И.М., Ветохин В.И. Физические основы механики почв. - К.: Феникс, 2008, - 266 с. Panov I.M., Vetohin V.I. Physical foundations of soil mechanics. Kiev, Phoenix, 2008, 266 pp. (In Russian).

[15] Ruysschaert G., Poesen J., Verstraeten G., Govers G. Soil losses due to mechanized potato harvesting. Soil Tillage Res., 86 (2006), pp. 52-72. 